\title{
Relation of anosognosia to frontal lobe dysfunction in Alzheimer's disease
}

\author{
A Michon, B Deweer, B Pillon, Y Agid, B Dubois
}

\begin{abstract}
A self-rating scale of memory functions was administered to 24 non-depressed patients with probable Alzheimer's disease, divided into two groups according to the overall severity of dementia (mild, mini-mental state (MMS) >21; moderate, MMS between 10 and 20). These groups did not significantly differ in their selfrating of memory functions. The same questionnaire was submitted to a member of each patient's family, who had to rate the patient's memory. An "anosognosia score" was defined as the difference between patient's and family's ratings. This score was highly variable, and covered, in the two groups, the full range between complete awareness of deficits and total anosognosia. Correlations between the anosognosia score and several neuropsychological data were searched for. No significant correlation was found with either the Wechsler memory scale, the MMS, or linguistic abilities and gestures. In contrast, this score was highly correlated with the "frontal score", defined as the sum of scores on the Wisconsin card sorting test (WCST), verbal fluency, Luria's graphic series, and "frontal behaviours" (prehension, utilisation, imitation behaviours, inertia, indifference). Among these tests of executive functions, the highest correlation with the anosognosia score was obtained on the WCST. This suggests that anosognosia in Alzheimer's disease is not related to the degree of cognitive deterioration but results, at least in part, from frontal dysfunction.
\end{abstract}

(F Neurol Neurosurg Psychiatry 1994;57:805-809)

INSERM U 289 and Service de Neurologie et Neuropsychologie,

Hôpital de la

Salpêtrière, Paris,

France

A Michon

B Deweer

B Pillon

Y Agid

B Dubois

Correspondence to: Dr Agnès Michon, Service de Agnes Mich deureurolot Neuropsychologie, Hôpital de la Salpêtrière, 47 Boulevard de l'Hôpital, 75651 Paris Cedex 13, France.

Received 19 April 1993 and in revised form

26 July 1993.

Accepted 30 September 1993

Anosognosia ${ }^{1}$ for physical disabilities or cognitive dysfunction has been noticed in various neurological disorders such as hemiplegia, hemianopia, and aphasias (see McGlynn and Schacter $^{2}$ for a review). As it is most often associated with deficits of the left part of the body, anosognosia has been postulated to result from a specific dysfunction of the right hemisphere. It is clear, however, that different forms of unawareness of deficits must be distinguished; for example, anosognosia has also been reported for memory deficits in different kinds of patients with amnesia ${ }^{3}$ and dementia ${ }^{4}$ at different stages of their disease. At a clinical level, if patients with Alzheimer's disease are generally aware of and anxious about their memory problems in the earliest stages of their disease ("forgetfulness phase"), they seem to progressively lose insight and to rate their memory impairment less severely as the disease progresses and memory functions deteriorate. $^{5}$

Few attempts have been made to investigate awareness of memory deficits in patients with dementia. Schacter et $a l^{6}$ showed that patients with Alzheimer's disease grossly overpredicted their performance on a verbal learning task compared with control subjects. Neary $e t a l^{7}$ found that different subgroups of patients with Alzheimer's disease showed different levels of awareness of deficits, suggesting a considerable degree of variability of anosognosia in this disease.

Relatively little is known about anosognosia in Alzheimer's disease, its relations with the stages of the disease, and its underlying mechanisms. Is it significantly related to memory loss (that is, do patients forget their deficits?), to an overall decline in intellectual functioning, or to a more specific cognitive disturbance?

To answer these questions, we investigated awareness of memory deficits in patients with Alzheimer's disease by: (a) analysing selfrating of memory functioning by patients in different stages of the disease; $(b)$ by comparing their self-ratings with ratings by relatives, the difference being indicative about patients' awareness of deficits; and (c) by searching for relations between anosognosia and several indices of cognitive functions, such as global deterioration scores, memory performance, instrumental activities, and executive functions.

\section{Patients and methods}

PATIENTS
Twenty-four patients with probable Alzheimer's disease, according to the NINCDS-ADRDA criteria, ${ }^{8}$ were included in this study. They were recruited by the memory clinic of the Hôpital de la Salpêtrière, where they were submitted to neuropsychological, neurological, and psychiatric examination before inclusion. They were divided into two subgroups as a function of the severity of their dementia, assessed with the minimental state (MMS) evaluation': 13 patients with mild dementia (MMS $=21$ or higher) and 11 with moderate dementia (MMS <21) (table 1). All patients were normal at neurological examination and serum analyses 
Table 1 Demographic and neuropsychological characteristics of patients with Alzheimer's disease

\begin{tabular}{lcl}
\hline & $\begin{array}{l}\text { Mild dementia } \\
(n=13)\end{array}$ & $\begin{array}{l}\text { Moderate dementia } \\
(n=11)\end{array}$ \\
\hline Sex ratio (M/F) & $5 / 8$ & $2 / 9$ \\
Age (years) & $72 \cdot 1(8 \cdot 2)$ & $73 \cdot 2(4 \cdot 8)$ \\
Mini-mental state & $23 \cdot 3(2 \cdot 2)$ & $16 \cdot 6(2 \cdot 4)$ \\
Wechsler memory scale & $84 \cdot 6(12)$ & $73 \cdot 8(7 \cdot 9)$ \\
Logical memory & $3 \cdot 80(1 \cdot 7)$ & $3 \cdot 22(1 \cdot 7)$ \\
Drawings & $2 \cdot 60(1 \cdot 5)$ & $0 \cdot 80(1 \cdot 2)$ \\
Paired associates & $6 \cdot 80(3 \cdot 0)$ & $6 \cdot 10(1 \cdot 8)$ \\
MADRS & $7 \cdot 6(5 \cdot 1)$ & $9 \cdot 45(6 \cdot 0)$ \\
\hline
\end{tabular}

Values are mean (SD).

(including thyroid hormones, vitamin B-12, folates, and syphilitic serology (VDRLTPHA), and the ischaemic score ${ }^{10}$ were not higher than four in any patient. Computed tomography or MRI, or both, showed mild atrophy without any further significant abnormalities or focal lesions (exclusion criterion). Depression was assessed with the Montgomery and Asberg rating scale ${ }^{11}$ (MADRS); a French version of this scale has been validated and compared with the Hamilton scale in subjects up to 69 years of age, and it was concluded that the two scales had the same sensitivity ${ }^{12}$; this scale has already been used with patients with mild to moderate dementia. ${ }^{13}$ The clinical diagnosis was based, after discussion between the psychiatrist and patients' spouse or relatives, on a psychiatric interview guided by the DSM III-R criteria. Informed consent was obtained after the nature of the procedure had been explained.

\section{METHODS}

Self-rating of memory dysfunction

All patients were given, before any neuropsychological testing, a self-rating questionnaire adapted from Squire and Zouzounis. ${ }^{14}$ Patients had to respond to 20 items that asked them to rate their memory abilities, by comparing their current ability level to "how it was five years ago". Ratings were made on a ninepoint scale from -4 through 0 to +4 , so that the total scores ranged from -80 to +80 . This questionnaire investigated different aspects of memory function (table 2). Subscores were calculated by adding the ratings of items which respectively assessed global evaluation (two items), recall (four items), retention (four items), remote memory for personal events (three items), attention (five items), and metamemory (two items). Self-rating profiles were obtained after transformation of these subscores into percentages of the maximum possible scores. The patients were guided by a staff member who, for each item, first asked him (her) if he or she was "worse than before, the same as before or better than before"; whenever the answer was "worse" or "better", the psychologist reminded that \pm 1 meant "a little bit", \pm 2 "moderately" \pm 3 "markedly", and \pm 4 meant "better (or worse) than ever". Such a procedure was rather time consuming, but allowed us to control that all patients reasonably understood the task.
Table 2 Self-rating scale of memory functions

1 My memory abilities are

2 My ability to search through my mind and recall names is

I think my relatives and acquaintances now judge my memory to be

4 My ability to hold in my memory things that I have learned is

My ability to recall things when I really try is

6 The tendency for a past memory to be "on the tip of the tongue", but not available to me is

My ability to remember the names and faces of people I meet is

8 My ability to know when the things I am paying attention to are going to stick in my memory is

9 My ability to remember things that have happened more than a year ago is

10 My ability now to remember what I read and what I watch on television is

11 My ability to make sense out of what people explain to me is

12 My ability to remember what I was doing after I have taken my mind off for a few minutes is

13 My ability to pay attention to what goes on around me is

14 If I were asked about it a month from now, my ability to remember this questionnaire would be

15 My ability to recall things which happened a long time ago is

16 My ability to recall what happened a few minutes ago is

7 My ability to follow what people are saying is

18 My general alertness to things happening around me is

9 My ability to recall things that happened during my childhood is

20 My ability to answer the questions asked to me is

For each item subjects were asked to judge their ability as it is now compared with five years ago. Subjects used a nine-point scale ranging from -4 (worse than ever before), through 0 (same as before), to +4 (better than ever before). Subscores were: global evaluation (items 1 and 3); attention (items 11 , were: global evaluation (items 1 and 3 ); attention (items 11 , $13,17,18$, and 20 ); retention (items $4,7,10$, and 12); recall 15 , and 19); metamemory (items 8 and 14).

Definition of the anosognosia score

The same rating questionnaire (in which "I" was replaced by "he" or "she") was submitted to the patients' relatives (in most instances spouse or children living with the patient) during the same session, with a different staff member. The difference between patient's total self-rating score and rating by the family member defined the anosognosia score. The largest was the difference, the most severe was anosognosia. Given the range of scoring, a difference higher than +25 points was considered as revealing severe anosognosia, whereas any score less than +5 corresponded to an awareness of deficits.

\section{Complementary tests}

All patients were submitted to a standard neuropsychological battery including: the MMS; the Wechsler memory scale with delayed testing for logical memory, visual memory, and paired associates; naming of 10 pictures of the Boston naming test, across all levels of difficulty; imitation of unimanual and bimanual meaningless gestures such as interlaced rings; copy of bidimensional drawings; and block design. Scores on these last three tests were combined into a "visuospatial score".

Executive functions were evaluated in 15 patients with the simplified version of the Wisconsin card sorting test (WCST), ${ }^{15}$ a verbal fluency test (names of animals and words beginning with " $M$ " in one minute ${ }^{16}$ ), and a graphic series requiring alternation between open squares and open triangles. ${ }^{17}$ Behavioural abnormalities (prehension, imitation, utilisation behaviours, inertia, indifference) observed in patients with frontal lesions $^{18}$ were also assessed separately on 
five-point scales. From the performance at these tasks, a "frontal score" was defined. ${ }^{19}$

\section{Statistical analyses}

The interrelations between the anosognosia score and the performance on cognitive and memory tests, MADRS, and tests of executive functions were analysed by linear correlations. Comparisons between groups of patients were calculated by analysis of variance.

\section{Results}

SELF-RATING OF MEMORY FUNCTIONS AND SEVERITY OF DEMENTIA

The two groups of patients (table 1) differed significantly in terms of global deterioration (MMS: $F[1,22]=46.05 ; p<0.0001$ ) and degree of memory impairment (Wechsler memory scale: $F[1,22]=5.59 ; p=0.027$ ), but not for depression (MADRS: $F[1,22]=$ $0.59 ; \mathrm{p}=0.45)$. Despite these differences, they showed similar profiles in their self-ratings of memory functions (fig 1), with the most severe self-rating scores relating to the global evaluation of memory abilities, and the less severe relating to attention and remote memory for personal events. Patients with moderate dementia tended to give more severe ratings than patients in the other group, but the difference did not reach the statistical significance for the overall rating scores $(p=0.35)$ and for the subscores of global evaluation $(p=0.25)$, attention $(p=$ $0.90)$, retention ( $p=0.57)$, and remote memory for personal events $(p=0 \cdot 47)$. This difference did not reach significance for the recall subscore $(F[1,22]=3.17 ; p=0.088)$, but was significant for the subscore for metamemory $(F[1,22]=5.40 ; p=0.029)$. Finally, there was no correlation between the severity of self-rating and either performance at the standard neuropsychological tests or depression.

Figure 1 Self-rating of
memory functions by
patients with Alzheimer's
disease with mild (solid
columns: MMS > 20) or
moderate (shaded
columns: $10<M M S<$
21) dementia. Scores are
transformed into
percentages of the
maximum possible scores.
Although patients with
moderate dementia tended
to rate themselves more
severely than patients in
the other group, the
difference was only
significant for the
metamemory subscore.

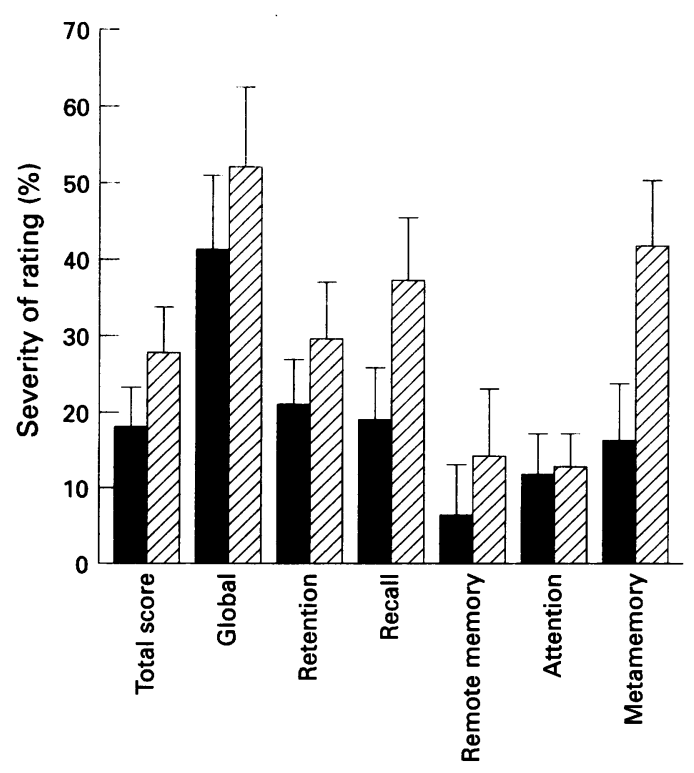

ANOSOGNOSIA SCORES AND COGNITIVE DETERIORATION

An anosognosia score was available for 22 patients (11 in each group). These scores were highly variable among patients and covered the full range between complete anosognosia (score $=+61$ ) and "hypergnosia"- that is, overestimation of the deficits by the patients compared with family members (score $=-30$ ). The distributions of these scores did not differ between patients with mild or moderate dementia: in the two groups, three patients were fully aware of their memory deficits (anosognosia score <+5) and six patients with mild dementia and five with moderate dementia showed severe anosognosia (anosognosia score $>25$ ).

Overall self-rating scores in the two groups of patients and rating scores by their relatives were submitted to an analysis of variance with repeated measures. Patients with moderate dementia tended to rate their memory functions more severely than patients in the other group, but the difference was not significant $(F[1,20]=0.90 ; p=0.35)$. The same tendency was observed with ratings of relatives $(\mathrm{F}[1,20]=2 \cdot 24 ; \mathrm{p}=0 \cdot 15)$. The differences between ratings by patients and by relatives were of the same order, however, $(17.36$ points for patients with moderate dementia $v$ 20.36 for patients in the other group; table 3). No significant interaction was found between degree of cognitive impairment (groups) and rater (patient $v$ relative: $F[1,20]=0.074$; $\mathrm{p}=0 \cdot 78)$.

No significant correlation was found between the anosognosia scores and the degree of global cognitive deterioration assessed by the MMS ( $r=0.29 ; p=0.19)$, memory impairment assessed by the Wechsler memory scale $(r=0.36 ; p=0 \cdot 11)$, linguistic abilities $(r=0.21 ; p=0.44)$, nor the visuospatial score (imitation of gestures, copy of drawings, block design; $r=0.40 ; p=0 \cdot 10$ ).

\section{ANOSOGNOSIA AND TESTS OF EXECUTIVE} FUNCTIONS

As stated earlier, 15 patients were also submitted to tests of executive functions; they were highly representative of the larger group as their mean (SD) MMS score was 20.6 (5.0) (range 13-26) and their mean (SD) Wechsler memory score was 78.5 (12.0) (range 58-99). With respect to executive functions, they displayed various degrees of impairment. On the WCST four had a normal performance and achieved four (three patients) or five (one patient) categories (normative data for age-matched controls: $4(0 \cdot 8)$ categories); one patient achieved three categories, and the other 10 only two or less. Verbal fluency was preserved in only three patients (normative data: 27 (5)), but was moderately to severely reduced in the others (range 19-8). In the same way three patients were normal on the graphic series (normative data: $9 / 10(0.5)$ ); the others ranged from 6 to $0 / 10$. Finally, all patients but two showed mild to moderate behavioural abnormalities (normative data: 20/20 (0)), ranging from 
Table 3 Rating of memory functions by patients with Alzheimer's disease and their relatives, and anosognosia score

\begin{tabular}{lll}
\hline Scores & $\begin{array}{l}\text { Mean (range) } \\
\text { score for patients with } \\
\text { mild dementia }\end{array}$ & $\begin{array}{l}\text { Mean (range) } \\
\text { score for patients with } \\
\text { moderate dementia }\end{array}$ \\
\hline $\begin{array}{l}\text { Patients' rating } \\
\text { Relatives' rating }\end{array}$ & $20 \cdot 82(-3$ to +41$)$ & $14 \cdot 18(-12$ to +50$)$ \\
Anosognosia score & $41 \cdot 18(+10$ to +57$)$ & $31 \cdot 54(+23$ to +66$)$ \\
\hline
\end{tabular}

A score of zero means that memory functions are considered to be exactly the same as they were "five years ago"; negative scores correspond to an estimated enhancement, positive scores to an impairment. The anosognosia mean scores (differences between ratings by patients and ratings by their relatives) are similar in the two groups; they cover the full range from complete anosognosia (positive differences) to"hypergnosia" (negative differences).

$18 / 20$ to $10 / 20 .^{19}$ Two patients had a frontal score which can be considered within the range of normal age-matched controls (normative data: $54 / 60$ (6)); the other scores ranged from $38 / 60$ to $19 / 60$.

The anosognosia score was highly correlated with the frontal score $(\mathrm{r}=0.70 ; \mathrm{p}=$ 0.0038 ) (fig 2). Among tests of executive functions the highest correlation appeared with the WCST $(r=0.72 ; p=0.0025)$.

\section{Discussion}

This study showed similar self-rating profiles in two groups of patients with Alzheimer's disease with different degrees of cognitive deterioration (mild or moderate dementia); these profiles were characterised by relatively less severe ratings for items tapping attentional abilities and remote memory for personal events, and were close to those already described by Squire and Zouzounis ${ }^{14}$ for several groups of patients with memory disorders, namely patients after electroconvulsive treatment, patients with non-Korsakoff amnesic syndrome, and patients with Korsakoff syndrome. This pattern corresponds with the common observation that attentional abilities and remote memory for personal events are relatively less impaired than other domains of memory and cognition in the early stages of Alzheimer's disease..$^{20-22}$ It suggests, as a whole, that self-rating of memory deficits by these patients with Alzheimer's disease can be considered as still fairly accurate.

The two groups of patients had similar overall self-rating and anosognosia scores, whatever the stage of the disease. Furthermore, there was no correlation between anosognosia scores and performance at the MMS or the cognitive or memory tests. These results, along with evidence that patients with amnesia with lesions restricted to the medial

Figure 2 Correlation between anosognosia scores and frontal scores in patients with Alzheimer's disease.

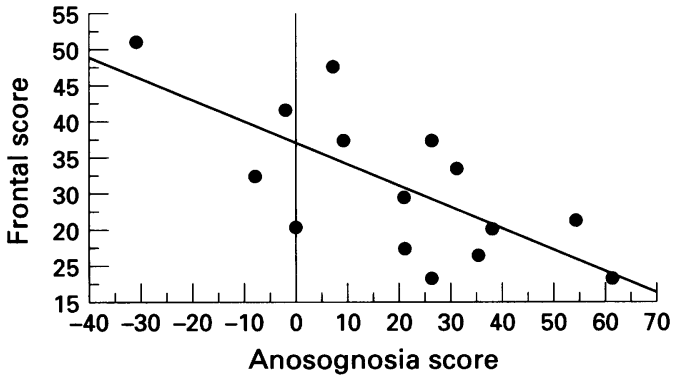

temporal lobes are well aware of their deficits $^{323}$ rule out the hypothesis according to which patients with Alzheimer's disease are anosognosic precisely because they forget that they have memory problems.

Contrasting with the similarity between the two groups of patients, the data also showed a high variability of anosognosia scores within each group: some patients overestimated their memory problems (compared with the rating of their relative), some were reasonably aware of their deficits, and others showed moderate to severe anosognosia. What factors might account for these discrepancies? Depression may provoke an overestimation of memory disorders, ${ }^{24}$ but no patient in this study was depressed and there was no correlation between the anosognosia scores and scores at the MADRS. The anosognosia score may also be dependent on the family awareness, tolerance, and burden, which are all likely to be modified throughout the course of the disease. There was, however, no relation with the severity of dementia, and the proportions of patients with and without anosognosia were the same in the two groups.

Anosognosia must therefore be considered as part of Alzheimer's disease, together with other cognitive and behavioural disorders. Moreover, the variability of anosognosia contributes to the heterogeneity of the disease..$^{25} 26$ If so, to which processes is it related? Correlational analyses showed that anosognosia was not related to the severity of dementia, memory, linguistic, or visuospatial disorders. In contrast, anosognosia scores were highly correlated with scores on tests of executive functions. These tests have been shown to be sensitive to a frontal lobe dysfunction: the WCST, ${ }^{27}$ lexical fluency tasks, ${ }^{16}$ graphic series, ${ }^{17}$ and the searching of behavioural disorders (utilisation and imitation behaviours ${ }^{18}$ ). These scores are also related to frontal dysfunction in degenerative diseases of the brain. ${ }^{28} 29$ Thus this strong correlation suggests that anosognosia is related to frontal lobe dysfunction, a hypothesis which has received support from a study of PET scans which showed some parallelism between frontal hypometabolism and anosognosia. ${ }^{29}$

Evidence from the domain of amnesia is consistent with this hypothesis. Numerous clinical observations ${ }^{3031}$ have shown little awareness of (and concern for) memory deficits in patients with Korsakoff's syndrome, who also show frontal lobe-like symptomatology. ${ }^{32} 33$ Additionally, patients with damage in the frontal regions after penetrating brain injury, ${ }^{34}$ or ruptured aneurysms of the anterior communicating artery, ${ }^{35}$ are known to be anosognosic for their memory deficits, in contrast with patients with amnesia without frontal signs, such as $\mathrm{NA}^{36}$ or $\mathrm{HM},{ }^{23}$ who have been reported as aware of their deficits. In the domain of dementias, several workers have argued $^{37}$ on the basis of clinical rating scales that early loss of insight is useful in differentiating Alzheimer's disease from Pick's disease, with earlier loss in the latter. Interestingly, the two dementias have generally been associated 
with signs of frontal lobe dysfunction, ${ }^{38}$ which is typically more pronounced in early Pick's disease than in early Alzheimer's disease.

The hypothesis according to which anosognosia in patients with amnesia is linked with frontal dysfunction has found additional support from studies using questionnaire methods to assess subjective memory impairment. ${ }^{39}$ This has been studied by Squire and Zouzounis ${ }^{14}$ using the same self-rating questionnaire; they showed that patients with Korsakoff's syndrome tended to report less severe memory impairment than six other non-Korsakoff patients with amnesia. McGlynn et $a^{39}$ compared two patients, one with frontal lesions and another with restricted left temporal lesions, and also found, by using several rating questionnaires, that unawareness of memory deficits was related to frontal damage.

1 Babinski MJ. Contribution à l'étude des troubles mentaux dans l'hémiplégie organique cérébrale (anosognosie) Rev Neurol 1914;12:845-8.

2 McGlynn SM, Schacter DL. Unawareness of deficits in neuropsychological syndromes. F Clin Exp Neuropsychol 1989;11:143-205.

3 Schacter DL. Unawareness of deficit and unawareness of knowledge in patients with memory disorders. In: Prigatano GP, Schacter DL, eds. Awareness of deficit after Prigatano GP, Schacter DL, eds. Awareness of deficit after brain injury: clinical and theoretical is

4 McGlynn SM, Kaszniak AW. Unawareness of deficits in dementia and schizophrenia. In: Prigatano GP, Schacter DL, eds. Awareness of deficit after brain injury: clinical and theoretical issues. New York: Oxford University Press, 1991:84-110

5 Schneck MK, Reisberg B, Ferris SH. An overview of current concepts of Alzheimer's disease. Am 7 Psychiatry 1982;139:165-73.

6 Schacter DL, McLachlan DR, Moscovitch R, Tulving E. Monitoring of recall performance by memory-disordered patients [abstract]. F Clin Exp Neuropsychol 1986;8:130.

7 patients [abstract]. 7 Clin Exp Neuropsychol 1986;8:130. psychological syndromes in presenile dementia due to psychological syndromes in presenile dementia due to
cerebral atrophy. $\mathcal{F}$ Neurol Neurosurg Psychiatry 1986;49: 163-74.

8 McKhann G, Drachman D, Folstein M, Katzman R, Price $D$, Stadlan EM. Clinical diagnosis of Alzheimer's disease: report of the NINCDS-ADRDA work group under the auspices of department of health and human services task force on Alzheimer's disease. Neurology 1984;34: 939-44

9 Folstein MF, Folstein SE, McHugh PR. "Mini Mental State": a practical method for grading the cognitive state of patients for the clinician. $\mathcal{F}$ Psychiatry Res 1975;12: $189-98$.

10 Hachinski VC, Iliff LD, Zilka E, et al. Cerebral blood flow in dementia. Arch Neurol 1975;32:632-7.

11 Montgomery SA, Asberg M. A new depression scale designed to be sensitive to change. Br $\mathcal{F}$ Psychiatry 1979; 134:382-9.

12 Pellet J, Bobon DP, Mormont L, Lang F, Massardier A. Etude princeps de validation française de la MADRS, sous-échelle dépression de la CPRS. In: Comptes-Rendus du Congrès de Psychiatrie et de Neurologie de Langue Française. Paris: Masson, 1975

13 Pillon B, Dubois B, Ploska A, Agid Y. Severity and speci- ficity of cognitive impairment in Alzheimer's, Huntington's, and Parkinson's diseases and progressive supranuclear palsy. Neurology 1991;41:634-43.

14 Squire LR, Zouzounis JA. Self-ratings of memory dysfunction: different findings in depression and amnesia. $7 \mathrm{Clin}$ Exp Neuropsychol 1988;10:727-38.

15 Nelson HE. A modified card sorting test sensitive to frontal lobe defect. Cortex 1976;12:313-24.

16 Benton AL. Differential behavioral effects in frontal lobe disease. Neuropsychologia 1968;6:53-60.

17 Luria AR. Higher cortical functions in man. New York: Basic Books, 1966.

18 Lhermitte F, Pillon B, Serdaru M. Human autonomy and the frontal lobes. Part 1: limitation and utilization behaviors: a neuropsychological study of 75 patients. Ann Neurol 1986;19:326-34.

19 Dubois B, Pillon B, Legault F, Agid Y, Lhermitte F. Slowing of cognitive processing in progressive supranuclear palsy: a comparison with Parkinson's disease. Arch Neurol 1988;45:1194-9.

20 Sagar HJ. Aging and age-related neurological disease: remote memory. In: Boller F, Grafman J, eds. Handbook of neuropsychology. Vol. 4. Amsterdam: Elsevier, 1990: $311-24$.

21 Spinnler $\mathrm{H}$. The role of attention disorders in the cognitive deficits of dementia. In: Boller F, Graftman J, eds. Handbook of neuropsychology. Vol. 5. Amsterdam: Handbook of neuropsych

22 Grady CL, Haxby JV, Horwitz B, et al. Longitudinal study of the early neuropsychological and cerebral metabolic changes in dementia of the Alzheimer type. $f$ Clin Exp Neuropsychol 1988;10:576-96.

23 Milner B, Corkin S, Teuber HL. Further analysis of the hippocampal amnesic syndrome: 14-year follow-up study of HM. Neuropsychologia 1968;6:215-34.

24 Plotkin DA, Mintz J, Jarvik LF. Subjective memory complaints in geriatric depression. Am f Psychiatry 1985; 142:1 103-5.

25 Haxby JV, Grady CL, Koss E, et al. Heterogeneous anterior-posterior metabolic patterns in dementia of the Alzheimer type. Neurology 1988;38:1853-63.

26 Celsis P, Agniel A, Puel M, Rascol A, Marc-Vergnes JP. Focal cerebral hypoperfusion and selective cognitive deficit in dementia of the Alzheimer type. $尹$ Neurol Neficit in dementia of the Alzheimer
Neuchiatry 1987;50:1602-12.

27 Milner B. Some effects of frontal lobectomy in man. In: Warren JM, Akert K, eds. The frontal granular cortex and behavior. New York: McGrawHill, 1964:313-31.

28 Blin J, Baron JC, Dubois B, et al. PET study in progressive supranuclear palsy: brain hypometabolism pattern and clinico-metabolic correlations. Arch Neurol 1990;47: 747-52.

29 Reed RR, Jagust WJ, Coulter R. Neuropsychological and cerebral perfusion correlates of anosognosia and depression in Alzheimer's disease [abstract]. $\mathcal{F}$ Clin Exp Neuropsychol 1991;13:110.

30 Korsakoff SS. Etude médico-psychologique sur une forme des maladies de la mémoire. Rev Philos 1889;5:501-30.

31 Zangwill OL. The amnesic syndrome. In: Whitty CWM, Zangwill O, eds. Amnesia. London: Butterworth, 1966: Zangwill

32 Butters N, Cermak LS. Alcoholic Korsakoff syndrome. New York: Academic Press, 1980

33 Squire LR. Memory and brain. New York: Oxford University Press, 1987.

34 Jahro L. Korsakoff-like amnesic syndrome in penetrating brain injury. Acta Neurol Scand 1973;49:44-67.

35 Luria AR. The neuropsychology of memory. New York Wiley, 1976.

36 Kaushall PI, Zetin M, Squire LR. A psychosocial study of chronic, circumscribed amnesia. $\mathcal{f}$ Nerv Ment Dis 1981 169:383-9.

37 Gustafson I, Nillson L. Differential diagnosis of presenile dementia on clinical grounds. Acta Psychiatry Scand 1982;65:194-207.

38 Kaszniak A. The neuropsychology of dementia. In: Grant J, Adams KM, eds. Neuropsychological assessment of neuropsychiatric disorders. New York: Oxford University Press, psychiatric disorder

39 McGlynn SM, Schacter DL, Glisky EL. Unawareness of deficits in organic amnesia [abstract]. $f$ Exp Clin Neuropsychol 1989;11:50. 